\title{
Acute myeloid leukemia: leukemia stem cells write a prognostic signature
}

\author{
Emma J Gudgin ${ }^{1,2}$ and Brian JP Huntly ${ }^{* 1,2}$
}

\begin{abstract}
In a recent interesting article, analysis of gene expression between phenotypically defined acute myeloid leukemia (AML) leukemia stem cells (LSCS) and more mature leukemia progenitor cells is used to generate a differentially expressed gene signature for LSCs. Through clever bioinformatic weighting analysis, the authors describe a method to convert this signature into a single score for any given sample and then test the prognostic utility of this 'LSC score' in publicly available gene expression profiles from bulk AML samples. They demonstrate that a high LSC score is associated with poor prognosis in AML patients and further demonstrate that the score is independent of known prognostic factors, including age, karyotype and mutation of the FLT3 or NPM1 genes. These findings are important and directly relate transcriptional dysregulation in AML LSCs with the outcome in patient samples, thus reinforcing the belief that these cellular populations are crucial for the initial propagation and subsequent relapse and resistance of leukemia.
\end{abstract}

Acute myeloid leukemia (AML) is an aggressive hematological malignancy characterized by a proliferation of primitive myeloid cells or 'blasts' in the blood. Although highly variable, most patients with AML will achieve a remission but later relapse and die from the disease. It is an extremely heterogeneous disease at the morphological, molecular and clinical levels with many distinct subgroups. Due to this heterogeneity, classification is critical to provide prognostic data informing risk-adapted therapeutic strategies, which have improved outcome dramatically in some subtypes of AML [1].

\footnotetext{
*Correspondence: bjph2@cam.ac.uk
}

'Department of Haematology, University of Cambridge, Cambridge Institute for Medical Research, Hills Road, Cambridge, CB2 OXY, UK

Full list of author information is available at the end of the article
To date, cytogenetic abnormalities have provided most prognostic information, although up to $50 \%$ of patients have a normal karyotype [2]. In addition, over the past decade the detection of specific molecular mutations, including mutations in the NPM1 and FLT-3 genes, have provided additional prognostic information to predict relapse and overall survival. Global gene expression profiles of bulk leukemia cells have provided further data to improve classification and prognosis $[3,4]$, and have identified overexpression of specific genes, such as $B A A L C$ and $E R G$, to be associated with poor survival. These studies have aided our understanding of the biology of AML as a disease characterized by transcriptional dysregulation [5].

Our understanding of the organization of malignancy and the basis of therapeutic failure have recently been informed by the demonstration that certain malignancies are arranged in hierarchies and have a cancer stem or initiating cell at their apices, which propagates and maintains the tumor [6]. The cancer stem cell hypothesis is controversial in some solid organ malignancies but is well accepted in leukemias, and AML was the first malignancy in which a cancer stem cell was demonstrated $[7,8]$. The malignant hierarchy in AML is similar to normal hematopoietic ontogeny, with leukemia stem cells (LSCs) in most AML patients being positive for the surface marker CD34, as are normal hematopoietic stem cells, and demonstrating variable expression of the CD38 and CD90 markers [7-10]. However, although it is thought that the LSC is responsible for disease relapse and secondary resistance, our understanding of this cellular compartment is poor and it is unlikely that significant therapeutic advances towards reducing disease relapse will be achieved until this ignorance is reversed. Specifically, it is not yet known whether the gene expression patterns in bulk tumor cells are reflective of the transcriptional dysregulation in their initiating or stem cells; this knowledge may inform our understanding of their biology and suggest therapeutic targets.

This issue is addressed in the interesting recent paper from Gentles and colleagues [11]. The authors compare gene expression profiles in LSCs and more differentiated 'leukemia progenitor cell' subpopulations from AML 
patients, as defined by surface phenotype during normal ontogeny (CD34+/CD38-/CD90- and CD34+/CD38+, respectively). Their dataset combines their own analysis of seven paired samples with a published dataset of eight paired gene expression profiles from LSCs that have been functionally validated in immunodeficient mice [12]. The authors found 52 genes to be differentially expressed, with the 21 genes down-regulated in the LSC fraction functionally enriched for genes involved in cell cycle, proliferation and differentiation, in keeping with the quiescent, differentiation-blocked phenotype predicted for LSCs. The 31 up-regulated genes were subsequently used to generate an 'LSC signature', where each gene was given a mathematical weighting relative to its predictive value within the dataset. The sum of these weightings could then be calculated for a given sample to obtain a single value or 'LSC score', and this score further correlated with clinical outcome and known prognostic factors. To address its prognostic value in AML patients, the 'LSC score' was recalculated using the same 31 genes in another dataset of gene expression profiles obtained from bulk blasts of 163 patients with normal karyotype AML. The authors demonstrated in this 'test' dataset that a high LSC score was associated with poorer overall survival, both as a continuous variable or a dichotomized value. Importantly, they validated these findings in the normal karyotype patients in another three large publicly available datasets of gene expression profiles across more diverse AML cases, and demonstrated similar findings in patients with cytogenetic abnormalities. Moreover, the independent prognostic value of the LSC score was shown by multivariate Cox regression analysis to be independent of known prognostic factors, including age, karyotype and mutation of the FLT3 or NPM1 genes.

These data are important findings and directly relate the genes dysregulated in LSCs with the outcome in patient samples, thus reinforcing the belief that these cellular populations are crucial for the propagation of leukemia. It is currently not practicable to predict $a$ priori prognosis in patients using global gene expression patterns of even bulk tumor cells, although it may be possible that elements of this signature could be used in quantitative PCR assays in the future, if the elements were further biologically validated and the assays standardized. Although the prognostic implications of this study are obvious, the biological implications are less so. The authors speculate that those leukemias with a high LSC score are likely to have an increased frequency of LSCs within the bulk tumor. This interpretation is reasonable and would be in keeping with two previous reports, one of which demonstrated that a high frequency of phenotypic LSCs at diagnosis of AML was predictive of a high minimal residual disease and poor overall survival [13]. The other, functional study demonstrated that the efficiency of disease transfer into immunocompromised mice (a function of LSC activity) was also predictive of the clinical outcome of the patient [14]. Unfortunately, no correlation of the frequency of the LSCs, as determined by surface phenotype, with the LSC score was provided, as this frequency could also provide a surrogate prognostic marker. In addition, this study may also provide indirect evidence of the target cell for transformation to generate LSCs in AML. The LSC score was also derived for the same 31-transcript gene set in normal hematopoietic stem cells and progenitor populations. Of note, the average LSC score for phenotypic AML LSCs was most comparable to the multipotent progenitor and granulocyte monocyte progenitor populations. These same compartments have recently been demonstrated to be expanded and to contain functional LSCs in the majority of AML cases [10]. Finally, of the 52 genes differentially expressed, only a few candidate genes have been previously implicated in leukemogenesis, including HLF [15], SETBP1 [16] and MEF2C [17]. Further evaluation of the other members of the gene set may yet provide even more information on the biology of the LSC in AML.

Abbreviations

AML, acute myeloid leukemia; LSC, leukemia stem cell.

Competing interests

The authors declare that they have no competing interests.

\section{Author details}

'Department of Haematology, University of Cambridge, Cambridge Institute for Medical Research, Hills Road, Cambridge, CB2 OXY, UK. ²Cambridge University Foundation Hospital Trust, Hills Road, Cambridge CB2 2QQ, UK

Published: 27 April 2011

\section{References}

1. Sanz MA, Montesinos P, Rayón C, Holowiecka A, de la Serna J, Milone G, de Lisa E, Brunet S, Rubio V, Ribera JM, Rivas C, Krsnik I, Bergua J, González J, Díaz-Mediavilla J, Rojas R, Manso F, Ossenkoppele G, González JD, Lowenberg B; PETHEMA and HOVON Groups: Risk-adapted treatment of acute promyelocytic leukemia based on all-trans retinoic acid and anthracycline with addition of cytarabine in consolidation therapy for high-risk patients: further improvements in treatment outcome. Blood 2010, 115:5137-5146.

2. Grimwade D, Hills RK, Moorman AV, Walker H, Chatters S, Goldstone AH, Wheatley K, Harrison CJ, Burnett AK; National Cancer Research Institute Adult Leukaemia Working Group: Refinement of cytogenetic classification in acute myeloid leukemia: determination of prognostic significance of rare recurring chromosomal abnormalities among 5876 younger adult patients treated in the United Kingdom Medical Research Council trials. Blood 2010, 116:354-365.

3. Valk PJ, Verhaak RG, Beijen MA, Erpelinck CA, Barjesteh van Waalwijk van Doorn-Khosrovani S, Boer JM, Beverloo HB, Moorhouse MJ, van der Spek PJ, Löwenberg B, Delwel R: Prognostically useful gene-expression profiles in acute myeloid leukemia. N Engl J Med 2004, 350:1617-1628.

4. Bullinger L, Döhner K, Bair E, Fröhling S, Schlenk RF, Tibshirani R, Döhner H, Pollack JR: Use of gene-expression profiling to identify prognostic subclasses in adult acute myeloid leukemia. N Engl J Med 2004, 350:1605-1616.

5. Tenen DG: Disruption of differentiation in human cancer: AML shows the way. Nat Rev Cancer 2003, 3:89-101.

6. Huntly BJ, Gilliland DG: Leukaemia stem cells and the evolution of cancerstem-cell research. Nat Rev Cancer 2005, 5:311-321. 
7. Lapidot T, Sirard C, Vormoor J, Murdoch B, Hoang T, Caceres-Cortes J, Minden M, Paterson B, Caligiuri MA, Dick JE: A cell initiating human acute myeloid leukaemia after transplantation into SCID mice. Nature 1994, 367:645-648.

8. Bonnet $\mathrm{D}$, Dick JE: Human acute myeloid leukemia is organized as a hierarchy that originates from a primitive hematopoietic cell. Nat Med 1997, 3:730-737.

9. Taussig DC, Vargaftig J, Miraki-Moud F, Griessinger E, Sharrock K, Luke T, Lillington D, Oakervee H, Cavenagh J, Agrawal SG, Lister TA, Gribben JG, Bonnet D: Leukemia-initiating cells from some acute myeloid leukemia patients with mutated nucleophosmin reside in the CD34(-) fraction. Blood 2010, 115:1976-1984.

10. Goardon N, Marchi E, Atzberger A, Quek L, Schuh A, Soneji S, Woll P, Mead A, Alford KA, Rout R, Chaudhury S, Gilkes A, Knapper S, Beldjord K, Begum S, Rose S, Geddes N, Griffiths M, Standen G, Sternberg A, Cavenagh J, Hunter H, Bowen D, Killick S, Robinson L, Price A, Macintyre E, Virgo P, Burnett A, Craddock C, et al.: Coexistence of LMPP-like and GMP-like leukemia stem cells in acute myeloid leukemia. Cancer Cell 2011, 19:138-152.

11. Gentles AJ, Plevritis SK, Majeti R, Alizadeh AA: Association of a leukemic stem cell gene expression signature with clinical outcomes in acute myeloid leukemia. JAMA 2010, 304:2706-2715.

12. Ishikawa F, Yoshida S, Saito Y, Hijikata A, Kitamura H, Tanaka S, Nakamura R, Tanaka T, Tomiyama H, Saito N, Fukata M, Miyamoto T, Lyons B, Ohshima K, Uchida N, Taniguchi S, Ohara O, Akashi K, Harada M, Shultz LD: Chemotherapy-resistant human AML stem cells home to and engraft within the bone-marrow endosteal region. Nat Biotechnol 2007 25:1315-1321
13. van Rhenen A, Feller N, Kelder A, Westra AH, Rombouts E, Zweegman S, van der Pol MA, Waisfisz Q, Ossenkoppele GJ, Schuurhuis GJ: High stem cell frequency in acute myeloid leukemia at diagnosis predicts high minimal residual disease and poor survival. Clin Cancer Res 2005, 11:6520-6527.

14. Pearce DJ, Taussig D, Zibara K, Smith LL, Ridler CM, Preudhomme C, Young $B D$, Rohatiner AZ, Lister TA, Bonnet D: AML engraftment in the NOD/SCID assay reflects the outcome of AML: implications for our understanding of the heterogeneity of AML. Blood 2006, 107:1166-1173.

15. Inaba T, Roberts WM, Shapiro LH, Jolly KW, Raimondi SC, Smith SD, Look AT: Fusion of the leucine zipper gene HLF to the E2A gene in human acute B-lineage leukemia. Science 1992, 257:531-534

16. Cristóbal I, Blanco FJ, Garcia-Orti L, Marcotegui N, Vicente C, Rifon J, Novo FJ, Bandres E, Calasanz MJ, Bernabeu C, Odero MD: SETBP1 overexpression is a novel leukemogenic mechanism that predicts adverse outcome in elderly patients with acute myeloid leukemia. Blood 2010, 115:615-625.

17. Krivtsov AV, Twomey D, Feng Z, Stubbs MC, Wang Y, Faber J, Levine JE, Wang J, Hahn WC, Gilliland DG, Golub TR, Armstrong SA: Transformation from committed progenitor to leukaemia stem cell initiated by MLL-AF9. Nature 2006, 442:818-822

doi:10.1186/scrt62

Cite this article as: Gudgin EJ, Huntly BJP: Acute myeloid leukemia: leukemia stem cells write a prognostic signature. Stem Cell Research \& Therapy 2011, 2:21. 